
Motrivivência
v. 28,
n. 47 ,
p. $145-159$
maio/2016

\title{
O FINANCIAMENTO DO ESPORTE EM SANTA CATARINA: o caso do FUNDESPORTE nos anos de 2011 e 2012
}

\author{
Sabrina Furtado \\ Edvardo Roberto May Effting ${ }^{2}$ \\ Suélen Barboza Giras de Castro 3 \\ Doralice Lange de Souza ${ }^{4}$
}

\section{RESUMO}

Em Santa Catarina o desenvolvimento do esporte encontra-se vinculado à Secretaria Estadual de Turismo, Cultura e Esporte, a qual através do FUNDESPORTE financia projetos esportivos no estado. O objetivo desta pesquisa, de cunho quantitativo, descritivo e exploratório foi o de investigar a distribuição dos recursos do FUNDESPORTE em 2011 e 2012. Durante estes anos, o mesmo cadastrou um total de 1.233 projetos, dos quais 317 efetivamente receberam repasse público. Do montante total, $R \$ 32.294 .026,97$, $94,4 \%$ foi repassado à pessoas jurídicas e $5,6 \%$ à pessoas físicas. Tanto as modalidades de esportes coletivos quanto individuais foram contempladas, sendo que algumas modalidades receberam significativamente mais recursos do que outras. A maior parte dos fundos foi destinada a projetos voltados ao esporte de alto rendimento e à realização de eventos esportivos de grande porte. Este trabalho pontua questões que podem servir como subsídios para futuros estudos e análise de casos similares.

Palavras-chave: Políticas Públicas; Financiamento; Esporte

1 Mestranda em Educação Física. UFPR, Curitiba/Paraná, Brasil. E-mail: sabrina_mfurtado@hotmail.com

2 Mestre em Educação Física. Professor da Universidade do Estado de Santa Catarina. UDESC, Florianópolis/ Santa Catarina, Brasil. E-mail: eduardoeffting58@gmail.com

3 Doutora em Educação Física. UFPR, Curitiba/Paraná, Brasil. E-mail: sueleneiras@hotmail.com

4 Doutora em Educação. Professora da Universidade Federal do Paraná. UFPR, Curitiba/Paraná, Brasil.

E-mail: desouzdo@yahoo.com 


\section{INTRODUÇÃO}

O direito a prática esportiva no Brasil foi instituído através da Constituição Federal de 1988. De acordo com esta legislação, o Estado brasileiro tem como dever o fomento de práticas esportivas formais e não formais como direito de cada cidadão, observando-se:

I. A autonomia das entidades desportivas, dirigentes e associações, quanto a sua organização e funcionamento;

II. A destinação de recursos para a promoção prioritária do desporte educacional e, em casos específicos para o desporto de alto rendimento;

III. O tratamento diferenciado para o desporto profissional e não profissional; IV. A proteção e o incentivo as manifestações desportivas de criação nacional; (BRASIL, 1988)

Ainda de acordo com a legislação, o esporte é reconhecido nas suas dimensões educacional, participação, rendimento e formação (BRASIL, 1998) ${ }^{5}$. Tanto a União, quanto os Estados e o Distrito Federal, têm competência concorrente para legislar sobre esta prática no país (BRASIL, 1988).

O Ministério do Esporte (ME) é o responsável pela administração do esporte em nível federal, e tem como competências a política nacional de desenvolvimento da prática de esportes; o intercâmbio com organismos voltados à promoção do esporte; o estímulo às iniciativas de incentivo às atividades esportivas; o planejamento, coordenação, supervisão e avaliação de planos e programas de incentivo ao esporte; a promoção de ações de democratização da prática esportiva; e a inclusão social por intermédio do esporte (BRASIL, 2003). Nas esferas estaduais, a administração do esporte encontra-se vinculada aos sistemas de esporte próprios dos estados e Distrito Federal. De acordo com a Lei Pelé (Lei 9.615/1998), estes sistemas devem ser organizados de maneira autônoma e em regime de colaboração com os demais sistemas de esporte. Já nos municípios, segundo a referida lei, a constituição de sistemas próprios de desportos é facultativa.

No caso específico do estado de Santa Catarina, o desenvolvimento do esporte encontra-se vinculado à Secretaria Estadual de Turismo, Cultura e Esporte (SOL). A SOL tem como missão promover o desenvolvimento e a integração das atividades turísticas, culturais e esportivas, visando a melhoria da qualidade de vida da população catarinense (SANTA CATARINA, 2009). Nesta secretaria, a política de esporte e lazer encontra-se vinculada à Fundação Catarinense de Esporte (FESPORTE). A FESPORTE tem por finalidade implementar e facilitar o desenvolvimento das políticas públicas do esporte catarinense, por meio da promoção de programas e projetos esportivos voltados à busca da excelência esportiva e ao bem-estar da população catarinense (FESPORTE, 2015).

A SOL, através do Fundo de Incentivo ao Esporte (FUNDESPORTE), financia projetos esportivos que estejam dentro de pelo um, de seus subprogramas, a saber: "incremento de atividades esportivas", "infraestrutura esportiva", "promoção e marketing", "esporte de rendimento",

5 A manifestação do esporte de formação foi incluída na legislação por meio da Lei nº 13.155/2015 (BRASIL, 2015). 
"esporte de participação", "esporte escolar e de inclusão" e "projetos especiais" ${ }^{6 " ~(S A N T A ~}$ CATARINA, 2008).

Os recursos financeiros do FUNDESPORTE são provenientes de:

I. recursos oriundos do FUNDOSO$\mathrm{CIAL}^{7}$;

II. de receitas decorrentes da aplicação de seus recursos;

III. contribuições, doações, financiamentos e recursos oriundos de entidades públicas ou privadas, nacionais ou estrangeiras;

IV. recursos provenientes da tributação de atividades lotéricas, na forma da Lei $\mathrm{n}^{\circ} 11.348$, de 17 de janeiro de 2000; e $V$. outros recursos que the venham ser destinados (SANTA CATARINA, 2008).

De acordo com a legislação do FUNDESPORTE, tem direito ao repasse dos recursos do fundo através da SOL os proponentes que forem pessoas jurídicas de direito público (que não seja da administração pública estadual), pessoa jurídica de direito privado sem fins lucrativos e pessoa física. Estes devem estar cadastrados no Sistema Estadual de Incentivo à Cultura, Turismo e ao Esporte (SEITEC), e apresentar no prazo estipulado de cada ano o plano de trabalho referente ao projeto, que deverá estar de acordo com o modelo padrão proposto pela secretaria (SANTA CATARINA, 2008).

Após o cadastramento do projeto, a SOL verifica a documentação entregue e, estando a mesma incompleta, o proponente do projeto é notificado e recebe um prazo para a sua adequação. Caso a documentação esteja de acordo com o solicitado, o projeto segue em tramitação para o setor jurídico para uma análise preliminar, passando então pelo comitê gestor de esporte para a emissão de um parecer. Uma vez aprovado, o projeto é repassado ao setor de planejamento para a realização de um pré-empenho. Em seguida, passa para o setor jurídico para publicação do contrato, depois para o setor financeiro para a efetivação do pagamento, e por fim para a gerência de fiscalização para prestação de contas. Sendo um projeto reprovado, o proponente do mesmo, dentro de um prazo previamente estipulado, pode pedir reconsideração do projeto e esse então retorna ao comitê gestor. Caso não haja o pedido, o projeto é arquivado.

Considerando-se a implantação do FUNDESPORTE no estado de Santa Catarina, esta pesquisa teve como objetivo mapear a alocação dos recursos do FUNDESPORTE no período de 2011 e 2012. Como objetivos específicos, esta pesquisa teve como propósitos: (1) Levantar os projetos que foram submetidos, arquivados, aprovados e pagos pelo FUNDESPORTE em 2011 e 2012; (2) Investigar a natureza física ou jurídica dos proponentes dos projetos que foram contemplados com recursos do FUNDESPORTE em 2011 e

6 Dentro da categoria de projetos especiais encontram-se: Fomento ao esporte de apresentação em modalidades esportivas não regulamentadas oficialmente; incentivo ao desenvolvimento de pesquisas na área do esporte e do lazer; apoio a ações que contemplem o esporte e o lazer sem impacto ambiental e estímulo à formação profissional dos responsáveis pelo esporte e pelo lazer em ambientes naturais.

7 Fundo de natureza financeira, ligado à Secretaria de Estado da Casa Civil do estado de Santa Catarina, destinado a financiar programas e ações de desenvolvimento, geração de emprego e renda, e inclusão e promoção social no campo e nas cidades, inclusive nas áreas de cultura, esporte e turismo, educação especial e educação superior. 
2012; e (3) Averiguar a alocação dos recursos do FUNDESPORTE de acordo com as modalidades esportivas. Vale observar que o financiamento do esporte no país ainda é uma temática pouco estudada na academia brasileira (VERONEZ, 2005; AMARAL; RIBEIRO; SILVA, 2014; ATHAYDE; MASCARENHAS; SALVADOR, 2015, CASTRO et al, 2015). Esta temática é ainda mais escassa no nível estadual. No caso específico do financiamento para o esporte no estado de Santa Catarina, localizamos apenas os estudos de Floss (2012), Wagner (2006) e Furtado (2014). Este trabalho expande os resultados anteriormente apresentados por Furtado (2014), uma vez que na presente versão apresenta dados relativos ao ano de 2012 e os contrasta com os dados de 2011. Além disto, um novo arcabouço teórico é trazido para a discussão. Visamos contribuir com a escassa produção científica na área, bem como gerar subsídios teóricos que possam contribuir para com a discussão e a gestão das políticas públicas de esporte e lazer no país.

\section{METODOLOGIA}

Este estudo se caracteriza como uma pesquisa quantitativa de cunho descritivo e exploratório. Os dados foram extraídos do Portal da Transparência do Poder Executivo de Santa Catarina ${ }^{8}$, através do Sistema Integrado de Planejamento e gestão Fiscal- SIGEF ${ }^{9}$. Neste portal, verificamos os pagamentos efetuados pelo FUNDESPORTE aos proponentes. Os dados também foram coletados do Sistema Estadual de Incentivo à Cultura, ao Turismo e ao Esporte - SEITEC ${ }^{10}$. Além dos dados financeiros, a utilização do SEITEC nos permitiu mapear o número de projetos, o parecer de cada projeto e o subprograma no qual cada um deles se enquadrava, e a natureza jurídica dos proponentes. Optamos por coletar informações apenas dos projetos que, ao serem submetidos por seus proponentes, receberam a delimitação de abrangência estadual, nacional e internacional. Ou seja, nossa coleta não envolveu os projetos de abrangência municipal e regional ${ }^{11}$. Optamos por assim fazer, uma vez que esses projetos são analisados em suas respectivas Secretarias de Desenvolvimento Regional, não passando pela gerência estadual da SOL, o que dificulta o acesso aos dados dos mesmos.

Os dados coletados a partir dos portais citados acima foram salvos e organizados em tabelas de acordo com os objetivos desta pesquisa e analisados com a ajuda do programa Microsoft Office Excel (versão 2007). Para análise dos pareceres dos projetos, utilizamos a seguinte nomenclatura: projetos submetidos, referentes àqueles que foram cadastrados no sistema da secretaria; projetos aprovados, referentes àqueles que atenderam todas as solicitações do edital e receberam parecer favorável dos setores responsáveis pela análise; projetos pagos, referentes aos que foram aprovados e que no momento da efetivação do pagamento não apresentavam débito com o estado ou a federação, e que a secretaria ainda dispunha de fundos para pagamento; projetos arquivados, referentes àqueles que não

8 http://www.sef.sc.gov.br/transparencia

9 http://www.sef.sc.gov.br/sistemas/sigef

$10 \mathrm{http}: / /$ sistemas.sc.gov.br/sol/seitec/

110 estado de Santa Catarina é dividido em 36 Secretarias de Desenvolvimento Regional (SDR's), dessa forma os projetos de abrangência regional visavam atender uma dessas 36 SDR's. 
estavam de acordo com as especificações citadas acima, ou então não atenderam às solicitações no tempo estipulado; e projetos encaminhados, referentes àqueles que foram encaminhados à SDR de origem ou então projetos que visavam contemplar outras áreas que não o esporte.

\section{RESULTADOS E DISCUSSÕES}

Nos anos de 2011 e 2012, o FUNDESPORTE cadastrou um total de 1.233 projetos, que de acordo com a tabela 1, receberam os seguintes pareceres:

Tabela 1- Pareceres dos projetos, por ano de submissão.

\begin{tabular}{lccc}
\hline Projetos & $\mathbf{2 0 1 1}$ & $\mathbf{2 0 1 2}$ & Total \\
\hline Submetidos & 645 & 588 & 1233 \\
Aprovados & 223 & 157 & 380 \\
Pagos & 204 & 113 & 317 \\
Arquivados & 402 & 436 & 838 \\
Encaminhados & 18 & 15 & 33 \\
\hline
\end{tabular}

Ao compararmos o número de projetos aprovados e pagos, observamos que houve um menor número de projetos aprovados (157) e efetivamente pagos (113) no ano de 2012 em relação ao ano de 2011, quando foram aprovados 223 e efetivamente pagos 204 projetos. Um dos fatores que pode ter contribuído para este decréscimo pode estar relacionado ao baixo orçamento disponibilizado ao FUNDESPORTE. No ano de 2011, o FUNDESPORTE teve um investimento de $\mathrm{R} \$ 23.688 .745,97,175 \%$ superior ao ano de 2012, onde o repasse foi de $\mathrm{R} \$ 8.605 .281,00$. Porém a variação do repasse recebido pelo SEITEC foi $24,4 \%$ menor no ano de 2012 em relação a 2011 (SANTA CATARINA, 2013). Tal realidade foi motivada pela baixa arrecadação do estado de Santa Catarina no ano de 2012, o que fez com que a maioria dos setores sofresse uma redução em seus orçamentos. O fundo em questão, no entanto, sofreu um maior corte de recursos, prejudicando, em tese, o desenvolvimento do esporte catarinense.
Um dos fatores que pode estar associado a um corte orçamentário mais expressivo na área do esporte em relação aos outros setores, é o fato de que, conforme apontam Athayde, Mascarenhas, Salvador (2015), a área do esporte e lazer não possui uma vinculação de receitas e nem despesas obrigatórias. Além disto, não há uma obrigatoriedade quanto a um repasse mínimo para o setor. Segundo Castro (2016), a vinculação de despesas à área do esporte vem sendo amplamente debatida no país. Algumas propostas solicitam que se vincule um percentual mínimo do orçamento público para repasse ao esporte nas três esferas governamentais (municipal, estadual e federal). Essas propostas foram apresentadas durante a I, II e III Conferência Nacional do Esporte, porém não houve qualquer regulamentação. Conforme apontam Starepravo, Mezzadri e Marchi Júnior (2015), o país privilegia o setor econômico em detrimento da área social, e dentro desta área, o esporte não é tido como prioritário. 
Além do decréscimo no orçamento, constatamos que nos dois anos analisados, o número de projetos arquivados foi significativo (62,3\% em 2011 e 74,1\% em 2012). Isto pode estar relacionado com as exigências burocráticas do FUNDESPORTE e a não adequação dos projetos às solicitações feitas pelo mesmo. Após análise dos pareceres dos projetos, verificamos que uma parcela significativa deles não foi aprovada por falta de documentação necessária ou ainda pelo não atendimento das solicitações feitas pelo FUNDESPORTE no prazo estipulado. A falta de capacitação técnica e organizacional dos redatores dos projetos é outro fator que pode ter inviabilizado a aprovação de grande parte dos projetos, o que também foi indicado por Matias e Athayde (2015) em um estudo que envolveu a esfera federal. Outro fator observado por Castro et. al (2015) que pode estar relacionado ao arquivamento de projetos, são irregularidades financeiras apresentadas pelos proponentes dos projetos no momento de receber a transação dos recursos aprovados pelo fundo, como por exemplo, inadimplência com o estado. Este tipo de situação impede o repasse por parte do fundo ao beneficiário em questão até que a situação seja regularizada pelo mesmo. Veronez (2005) aponta que para a celebração de convênios através de programas governamentais, os proponentes devem apresentar uma extensa documentação, como certidões negativas, detalhamento de ações do projeto, especificação de recursos necessários a cada uma dessas etapas, e que ainda tais documentos têm um prazo de validade curto. Segundo o autor, esses fatores tornam o processo bastante burocrático levando as instituições a abandonarem o processo de aprovação dos projetos. Athayde (2009) ao avaliar a gestão do programa governamental
"Segundo Tempo", também aponta que em certas circunstâncias existem "excessos burocráticos" por parte do órgão responsável pela aprovação dos projetos em suas diferentes etapas de análise. Embora o autor tenha analisado um programa do governo federal em parceria com governos estaduais e não o FUNDESPORTE, é possível que esta realidade se aplique ao mesmo, dificultando a submissão e aprovação de projetos

Em ambos os anos os proponentes de natureza jurídica receberam um valor maior que os proponentes de natureza física. Do total de recursos pagos no ano de $2011, R \$ 1.287 .048,06$ foram destinados à pessoas físicas e $\mathrm{R} \$ 22.717 .153,41$ à pessoas jurídicas. Já em 2012, R\$ 510.274,00 foram alocados para pessoas físicas e $\mathrm{R} \$$ 8.095.007,00 para pessoas jurídicas. Sendo assim, no somatório do período, $5,6 \%$ dos recursos foram destinados à pessoas físicas e $94,4 \%$ à pessoas jurídicas. Um fator que pode ter influenciado esta configuração é que durante o período analisado, o estado de Santa Catarina foi sede de eventos esportivos de grande porte. Estes eventos foram propostos por unidades jurídicas, como federações esportivas, fundações e empresas. Neste período, ocorreram campeonatos tais como o Ironman Brasil (prova de Triathlon de longa distância), a Volvo Ocean Race (regata mundial com etapa em Santa Catarina), a Corrida das Estrelas (prova de Automobilismo) e os jogos Abertos de Santa Catarina.

Alguns autores questionam a realização destes eventos, uma vez que os recursos neles empregados em muitos casos atendem apenas os interesses de empresas privadas e do próprio governo, deixando de lado interesses do cidadão comum (COAKLEY; SOUZA, 2013; MATIAS; ATHAYDE, 2015). 
Outro questionamento que pode ainda ser feito, é que em alguns casos, a infraestrutura construída para a realização de determinados eventos esportivos é inacessível para grande parte da população, o que pode prejudicar ainda mais o processo de democratização do acesso ao esporte por parte da população (COAKLEY; SOUZA, 2013).

Os projetos provenientes de pessoas físicas totalizaram um orçamento significativamente mais baixo em relação aos de natureza jurídica, pois financiaram apenas um atleta, e não uma equipe como nos esportes coletivos, ou então a realização de um evento esportivo como ocorre com os proponentes de ordem jurídica. Além desse fator, conforme destacado por Santos (1997), os atletas contam também com o patrocínio de empresas privadas, o que contribui para um menor orçamento de projetos oriundos de pessoas físicas. Vale destacar que esta ação também contribui para a não democratização do acesso ao esporte por parte da população, uma vez que destina recursos do fundo a atletas de alto rendimento.

Dentre as modalidades de esporte coletivo que receberam recursos do FUNDESPORTE, o Futebol foi a que recebeu o maior valor de repasses, somando nos dois anos analisados um total de $39.7 \%$. Com relação ao número de projetos aprovados, a modalidade que obteve maior destaque foi o Vôlei, que aprovou 10 projetos. Vide tabela abaixo:

Tabela 2 - Modalidades esportivas coletivas por número de projetos aprovados e valor de recursos recebidos por ano analisado

\begin{tabular}{|c|c|c|c|c|c|}
\hline Modalidade & Projetos & 2011 & 2012 & TOTAL & $\%$ do total \\
\hline \multirow{2}{*}{ Futebol } & $N^{\circ}$. & 5 & 1 & 6 & $15,3 \%$ \\
\hline & $\mathrm{R} \$$ & $1.803 .648,50$ & $1.500 .000,00$ & $3.303 .648,50$ & $39,7 \%$ \\
\hline \multirow{2}{*}{ Futsal } & $N^{0}$. & 6 & 2 & 8 & $20,5 \%$ \\
\hline & $\mathrm{R} \$$ & $1.765 .000,00$ & $650.000,00$ & $2.415 .000,00$ & $29,0 \%$ \\
\hline \multirow{2}{*}{ Vôlei } & $N^{\circ}$. & 7 & 3 & 10 & $25,6 \%$ \\
\hline & $\mathrm{R} \$$ & $1.065 .000,00$ & $352.500,00$ & $1.417 .500,00$ & $17,0 \%$ \\
\hline \multirow{2}{*}{ Basquete } & $N^{\circ}$. & 4 & 1 & 5 & $12,8 \%$ \\
\hline & $\mathrm{R} \$$ & $480.000,00$ & $200.000,00$ & $680.000,00$ & $8,1 \%$ \\
\hline \multirow{2}{*}{ Ginástica rítmica } & $N^{\circ}$. & 0 & 1 & 1 & $2,5 \%$ \\
\hline & $\mathrm{R} \$$ & 0,00 & $200.000,00$ & $200.000,00$ & $2,4 \%$ \\
\hline \multirow{2}{*}{ Handebol } & $N^{\circ}$. & 4 & 0 & 4 & $10,2 \%$ \\
\hline & $\mathrm{R} \$$ & $127.820,00$ & 0,00 & $127.820,00$ & $1,5 \%$ \\
\hline \multirow{2}{*}{ Bocha e bolão } & $N^{\circ}$. & 3 & 0 & 3 & $7,6 \%$ \\
\hline & $\mathrm{R} \$$ & $89.500,00$ & 0,00 & $89.500,00$ & $1 \%$ \\
\hline \multirow{2}{*}{$\begin{array}{l}\text { Ginástica } \\
\text { artística }\end{array}$} & $N^{\circ}$. & 2 & 0 & 2 & $5,1 \%$ \\
\hline & $\mathrm{R} \$$ & $83.000,00$ & 0,00 & $83.000,00$ & $0,9 \%$ \\
\hline \multirow{2}{*}{ Total } & $\mathrm{N}^{\circ}$. & 31 & 8 & 39 & \\
\hline & $\mathbf{R} \$$ & $5.286 .148,50$ & $2.902 .500,00$ & $8.316 .468,50$ & \\
\hline
\end{tabular}


É possível observar que não houve uma continuidade no número de projetos aprovados em 2012 em nenhuma das modalidades apresentadas. Além disso, algumas modalidades como a Bocha e Bolão, Ginástica Artística, Ginástica Rítmica e Handebol não contaram com nenhum projeto aprovado em 2012. Isto pode ter sido motivado pela falta de planejamento em longo prazo das equipes e instituições para que os projetos pudessem ter continuidade. Outro fator que pode ter motivado essa descontinuidade é o modelo de gestão do FUNDESPORTE, o qual estipula editais para proposição de projetos com duração de até um ano. Esta limitação de prazo pode levar à descontinuidade das ações de um ano para outro, uma vez que os projetos que foram aprovados em um ano, não necessariamente serão aprovados no ano subsequente.

Faz-se interessante ressaltar que é notória a soma recebida pelo Futebol, que no ano de 2012 com apenas um projeto aprovado, recebeu um repasse no valor de
$\mathrm{R} \$ 1.500 .000,00$. Este projeto foi proposto pelo Instituto Avaí Futebol Clube para a formação de categorias de base. Achados similares em relação ao favorecimento do futebol na esfera federal foram encontrados por Matias e Athayde (2015). Segundo estes pesquisadores, os clubes privados de Futebol detêm um total de $8 \%$ de todo o recurso captado pela Lei de Incentivo ao Esporte, entre os anos de 2007 e 2013. Esta lógica de financiamento prioritário do futebol, modalidade já bastante difundida no país, prejudica a descentralização de recursos em prol de outras modalidades esportivas que necessitam de mais incentivos.

Com relação às modalidades individuais, o latismo foi a que recebeu o maior repasse, somando nos anos analisados $R \$ 3.865 .430,00$. Este foi seguido pelos Esportes Radicais ${ }^{12}$ que receberam $\mathrm{R} \$ 3.610 .642,06$ e aprovaram entre 2011 e 2012 o maior número de projetos (49). Vide as modalidades aprovadas abaixo (TABELA 3).

Tabela 3 - Modalidades esportivas individuais por número de projetos aprovados e valor de recursos recebidos por ano analisado.

\begin{tabular}{lccccc}
\hline Modalidade & Projetos & $\mathbf{2 0 1 1}$ & $\mathbf{2 0 1 2}$ & Total & \% do total \\
\hline \multirow{2}{*}{ latismo } & $\mathrm{N}^{\circ}$. & 11 & 2 & 13 & $5,3 \%$ \\
& $\mathrm{R} \$$ & $3.818 .430,00$ & $47.000,00$ & $3.865 .430,00$ & $30,1 \%$ \\
\multirow{2}{*}{ Esportes radicais } & $\mathrm{N}^{\circ}$. & 32 & 17 & 49 & $20,3 \%$ \\
& $\mathrm{R} \$$ & $2.806 .642,06$ & $804.000,00$ & $3.610 .642,06$ & $28,1 \%$ \\
\multirow{5}{*}{ Triathlon } & $\mathrm{N}^{\circ}$ & 20 & 10 & 30 & $12,4 \%$ \\
& $\mathrm{R} \$$ & $1.068 .032,00$ & $759.000,00$ & $1.827 .032,00$ & $14,2 \%$ \\
\hline
\end{tabular}

12 Para melhor configuração da tabela as modalidades Body Board, Canoagem, Jet Ski, Kitsurf, Parapente, Skate, Stand Up e Surf foram agrupadas na modalidade Esportes Radicais. 
V. $28, n^{\circ} 47$, maio/2016

\begin{tabular}{|c|c|c|c|c|c|}
\hline Modalidade & Projetos & 2011 & 2012 & Total & $\%$ do total \\
\hline \multirow{2}{*}{ Corrida de rua } & $\mathrm{N}^{\circ}$ & 6 & 5 & 11 & $4,5 \%$ \\
\hline & $\mathrm{R} \$$ & $730.600,00$ & $480.000,00$ & $1.210 .600,00$ & $9,4 \%$ \\
\hline \multirow{2}{*}{ Lutas $^{13}$} & $\mathrm{~N}^{\circ}$. & 17 & 18 & 35 & $14,5 \%$ \\
\hline & $\mathrm{R} \$$ & $444.638,75$ & $545.219,00$ & $989.857,75$ & $7,7 \%$ \\
\hline \multirow{2}{*}{ Motociclismo } & $\mathrm{N}^{\circ}$. & 8 & 4 & 12 & $4,9 \%$ \\
\hline & $\mathrm{R} \$$ & $632.200,00$ & $107.500,00$ & $739.700,00$ & $5,7 \%$ \\
\hline \multirow{2}{*}{ Tênis } & $\mathrm{N}^{\circ}$. & 16 & 10 & 26 & $10,7 \%$ \\
\hline & $\mathrm{R} \$$ & $588.869,00$ & $80.000,00$ & $668.869,00$ & $5,2 \%$ \\
\hline \multirow{2}{*}{ Automobilismo } & $N^{\circ}$. & 3 & 4 & 7 & $2,9 \%$ \\
\hline & $\mathrm{R} \$$ & $480.000,00$ & $100.000,00$ & $580.000,00$ & $4,5 \%$ \\
\hline \multirow{2}{*}{ Atletismo } & $\mathrm{N}^{\circ}$ & 4 & 6 & 10 & $4,1 \%$ \\
\hline & $\mathrm{R} \$$ & $263.000,00$ & $60.500,00$ & $323.500,00$ & $2,5 \%$ \\
\hline \multirow{2}{*}{ Ciclismo } & $N^{\circ}$. & 0 & 4 & 4 & $1,6 \%$ \\
\hline & $\mathrm{R} \$$ & 0 & $215.000,00$ & $215.000,00$ & $1,6 \%$ \\
\hline \multirow{2}{*}{ Hipismo } & $\mathrm{N}^{\circ}$ & 12 & 6 & 18 & $7,4 \%$ \\
\hline & $\mathrm{R} \$$ & $171.480,00$ & $23.500,00$ & $194.980,00$ & $1,5 \%$ \\
\hline \multirow{2}{*}{ Golfe } & $N^{\circ}$ & 2 & 0 & 2 & $0,8 \%$ \\
\hline & $\mathrm{R} \$$ & $140.660,00$ & 0 & $140.660,00$ & $1,0 \%$ \\
\hline \multirow{2}{*}{ Natação } & $\mathrm{N}^{\circ}$. & 3 & 3 & 6 & $2,4 \%$ \\
\hline & $\mathrm{R} \$$ & $125.437,60$ & $8.500,00$ & $133.937,60$ & $1,0 \%$ \\
\hline \multirow{2}{*}{ Xadrez } & $\mathrm{N}^{\circ}$. & 4 & 3 & 7 & $2,9 \%$ \\
\hline & $\mathrm{R} \$$ & $84.200,00$ & $18.000,00$ & $102.200,00$ & $0,7 \%$ \\
\hline \multirow{2}{*}{ Remo } & $\mathrm{N}^{\circ}$. & 3 & 2 & 5 & $2,0 \%$ \\
\hline & $\mathrm{R} \$$ & $90.130,00$ & $12.000,00$ & $102.130,00$ & $0,7 \%$ \\
\hline \multirow{2}{*}{ Punhobol } & $N^{0}$ & 0 & 1 & 1 & $0,4 \%$ \\
\hline & $\mathrm{R} \$$ & 0 & 80.000 & 80.000 & $0,6 \%$ \\
\hline \multirow{2}{*}{ Tiro com arco } & $N^{\circ}$ & 1 & 0 & 1 & $0,4 \%$ \\
\hline & $\mathrm{R} \$$ & $22.296,00$ & 0 & $22.296,00$ & $0,1 \%$ \\
\hline \multirow{2}{*}{ Patinação } & $N^{\circ}$ & 2 & 0 & 2 & $0,8 \%$ \\
\hline & $\mathrm{R} \$$ & $19.820,00$ & 0 & $19.820,00$ & $0,1 \%$ \\
\hline \multirow{2}{*}{ Tiro ao alvo } & $N^{\circ}$ & 1 & 0 & 1 & $0,4 \%$ \\
\hline & $\mathrm{R} \$$ & $13.000,00$ & 0 & $13.000,00$ & $0,1 \%$ \\
\hline \multirow{2}{*}{ Duathlon } & $\mathrm{N}^{0}$. & 0 & 1 & 1 & $0,4 \%$ \\
\hline & $\mathrm{R} \$$ & 0 & $5.000,00$ & $5.000,00$ & $0,03 \%$ \\
\hline \multirow{2}{*}{ Total } & $N^{\circ}$. & 145 & 96 & 241 & \\
\hline & $\mathrm{R} \$$ & $8.771 .333,41$ & $4.057 .219,00$ & $12.828 .552,41$ & \\
\hline
\end{tabular}


Conforme a tabela acima, algumas modalidades apresentaram certa regularidade quanto ao número de projetos aprovados nos diferentes anos (Atletismo, Corrida de Rua, Natação, Lutas), ao contrário do que aconteceu com as modalidades coletivas. A modalidade de latismo aprovou um número considerável de projetos no ano de 2011, e recebeu um valor substantivo de recursos em relação às demais modalidades. Este repasse maior para o latismo em detrimento de outras modalidades, que em alguns casos aprovaram até mais projetos que ele (como por exemplo, o Tênis), foi motivado por um evento internacional de alto rendimento da modalidade sediado no estado, que em uma única edição no ano de 2011, recebeu uma soma de R\$3.000.000,00. O mesmo ocorreu com o Triathlon, que também aprovou um número de projetos expressivo, se comparado às demais modalidades que receberam repasses do fundo, e também apresentou um orçamento alto devido ao repasse feito para a realização de uma prova de Triathlon de longa distância (Ironman) no estado.

Os eventos dedicados ao esporte de alto rendimento demandaram um investimento elevado do FUNDESPORTE quando considerado o orçamento total do Fundo. Por lei, este deveria priorizar o esporte educacional (BRASIL, 1988). A acentuada destinação de recursos ao esporte de rendimento, que por sua vez possui um maior valor de mercado do que o esporte educacional e de participação, também foi verificada no âmbito federal (ATHAYDE; MASCARENHAS; SALVADOR, 2015; MATIAS; ATHAYDE, 2015; CASTRO et al, 2015; ALMEIDA; MARCHI JUNIOR, 2010). Castro et al (2015), por exemplo, observam que há um interesse por parte do governo em financiar o esporte de alto rendimento em razão de sua expressividade perante a mídia e consequente visibilidade pública e valor de mercado. Almeida e Marchi Junior (2010), que identificaram um elevado volume de repasses em âmbito federal à realização de megaeventos esportivos no Brasil, reafirmam o que vários autores de âmbito internacional têm apontado: que existem interesses políticos na projeção de países sede, como o nosso, através de grandes eventos esportivos, uma vez que estes são acompanhados mundialmente. Esta lógica de projeção e visibilidade do local sede dos eventos, pode estar motivando o financiamento de grandes eventos esportivos no estado de Santa Catarina, a fim de projetar o estado no cenário nacional ou até mesmo internacional.

Conforme apontam Matias e Athayde (2015), a hegemonia do esporte de rendimento também pode ser verificada tanto em propostas quanto em volume de recursos aprovados e captados através da Lei do Incentivo Fiscal na esfera federal. Conforme apontam estes autores, essa manifestação esportiva atende a uma pequena parcela da população e beneficia a indústria esportiva e do entretenimento. Ainda segundo os autores, a destinação de recursos públicos para o esporte de alto rendimento amplia a desigualdade de acesso da população ao esporte, pois, também, como reforçam Castro et. al. (2015), nesse caso, o esporte é visto como um negócio rentável e não como um direito do cidadão brasileiro.

Ainda analisando os dados referentes às modalidades individuais, é possível verificar que grande parte dos projetos são submetidos pelos próprios atletas, que visam o alto rendimento no esporte. Esse pode ser um dos motivos pelo qual há um 
número maior de projetos aprovados. No caso das modalidades coletivas, um só projeto atende a toda equipe.

Além de projetos ligados diretamente à modalidades esportivas específicas, o
FUNDESPORTE aprovou também projetos ligados aos demais setores do campo esportivo, conforme pode ser visualizado na tabela 4 .

Tabela 4 - Outros projetos aprovados em 2011 e 2012.

\begin{tabular}{lccccc}
\hline Modalidade & Projetos & $\mathbf{2 0 1 1}$ & $\mathbf{2 0 1 2}$ & Total & \% do total \\
\hline \multirow{2}{*}{ Poliesportivos } & $\mathrm{N}^{\circ}$ & 16 & 5 & 21 & $44,6 \%$ \\
& $\mathrm{R} \$$ & $3.776 .993,46$ & $1.125 .000,00$ & $4.901 .993,46$ & $47,4 \%$ \\
\multirow{2}{*}{ Outros } & $\mathrm{N}^{\circ}$ & 11 & 3 & 14 & $29,7 \%$ \\
& $\mathrm{R} \$$ & $2.520 .300,00$ & $545.062,00$ & $3.065 .362,00$ & $29,7 \%$ \\
Infraestrutura & $\mathrm{N}^{\circ}$ & 5 & 3 & 8 & $17,0 \%$ \\
\multirow{2}{*}{ Poliesportivos } & $\mathrm{R} \$$ & $1.594 .000,00$ & $600.000,00$ & $2.194 .000,00$ & $21,2 \%$ \\
adaptados & $\mathrm{N}^{\circ}$ & 4 & 0 & 4 & $8,5 \%$ \\
\hline \multirow{2}{*}{ Total } & $\mathrm{R} \$$ & $161.059,60$ & 0,00 & $161.059,60$ & $1,5 \%$ \\
\hline
\end{tabular}

Os projetos identificados na tabela como "Poliesportivos" e "Poliesportivos adaptados ${ }^{13 "}$, contemplaram mais de uma modalidade esportiva. Conforme se pode observar acima, no ano de 2011, a categoria "Poliesportivos" aprovou um elevado número de projetos e recebeu um repasse alto. Esta categoria recebeu um repasse significativo devido à realização dos Jogos Abertos de Santa Catarina. De 2011 para 2012, no entanto, houve uma queda acentuada no número de projetos aprovados na referida categoria. A categoria "Outros", na qual foram incluídos projetos esportivos como Fóruns, Seminários e demais eventos de capacitação profissional na área esportiva, também aprovou uma quantia significativa de projetos principalmente em 2011. Em 2012 houve uma queda de recursos destinados à mesma. $\mathrm{O}$ mesmo ocorreu com a categoria "Infraestrutura", que apresentou uma diminuição no número de projetos aprovados. Estes projetos estavam relacionados a reformas ou então a construção de locais para prática esportiva

Os dados apresentados revelam que houve uma descontinuidade no financiamento de projetos esportivos, via FUNDESPORTE, no estado de Santa Catarina. Ou seja, de um ano para o outro o financiamento para uma ou outra prática foi interrompido, o que provavelmente dificultou o acesso e a continuidade da prática esportiva por parte de pessoas interessadas. Os dados

13 Esportes adaptados são manifestações esportivas modificadas, a fim de atender as necessidades de pessoas com deficiências físicas e/ou intelectuais. 
também revelam que, embora tenha havido predomínio de investimentos no futebol, o estado de Santa Catarina financiou também outras modalidades. Este financiamento, no entanto, tal como acontece no âmbito federal (ALMEIDA; MARCHI JUNIOR, 2010; CASTRO et al, 2015; ATHAYDE; MASCARENHAS; SALVADOR, 2015; MATIAS; ATHAYDE, 2015), se concentrou no esporte de alto rendimento e na realização de eventos esportivos de grande porte. Esta tendência provavelmente compromete o acesso ao esporte por parte da população.

\section{CONSIDERAÇÕES FINAIS}

Houve em 2011 e 2012 uma demanda representativa no número de projetos submetidos ao FUNDESPORTE (1.233), porém desse total, $68 \%$ foi arquivada. Alguns fatores como o corte orçamentário sofrido em 2012, a falta de capacitação técnica e organizacional dos redatores dos projetos, a falta de documentação necessária ou ainda o não cumprimento das solicitações feitas pelo FUNDESPORTE no prazo estipulado pelos proponentes dos projetos, podem ter contribuído para essa realidade. As exigências burocráticas do órgão provavelmente também contribuíram para com o problema.

Grande parte dos recursos destinados ao esporte em Santa Catarina tanto para os proponentes de ordem jurídica quanto individual foram repassados para o esporte de alto rendimento e mais especificamente, para o financiamento de eventos de grande porte. Como citamos anteriormente, estudos acerca do tema vêm apontando que essa característica pode estar atrelada a interesses particulares, como por exemplo, demandas de empresas privadas que buscam se beneficiar de verbas públicas buscando visibilidade para a sua marca através do esporte. Outros fatores podem estar relacionados com interesses políticos e partidários ligados a projetos contemplados com recursos públicos. Esta realidade pode estar associada à capacidade do esporte de rendimento de mobilizar interesses. Ela pode também estar relacionada com a maior capacidade de agentes com interesses nestas áreas de submeterem e aprovarem projetos.

No tocante ao financiamento de modalidades esportivas via FUNDESPOR$\mathrm{TE}$, há uma descontinuidade de projetos, o que provavelmente dificulta o acesso e a continuidade da prática esportiva por parte da população. Também há uma discrepância tanto em valores repassados quanto em número de projetos aprovados nas distintas modalidades. O valor do repasse recebido por modalidade esportiva, em grande parte, esteve ligado às finalidades específicas dos projetos propostos, como no caso da realização dos eventos de grande porte para a Vela e Triathlon.

O presente estudo se restringiu aos anos de 2011 e 2012. A análise de dois anos é insuficiente para apontar tendências acerca do financiamento público do esporte em Santa Catarina, não sendo possível fazer afirmações quanto ao comportamento orçamentário do fundo em questão em um recorte temporal mais amplo. Esta análise, no entanto, pontua questões relativas ao financiamento de projetos no estado que podem servir como subsídios para a análise de outros períodos temporais e casos similares.

O financiamento esportivo é um campo amplo e dinâmico, suscetível a constantes mudanças que vão desde o campo político até o econômico em diferentes esferas (municipal, estadual e federal). Desta 
forma, faz-se necessário a ampliação do recorte temporal aqui analisado. Também se fazem necessários outros estudos sobre diferentes órgãos financiadores do esporte e sobre as nuances que atuam na configuração do campo esportivo.

\section{REFERÊNCIAS}

ALMEIDA, B. S.; MARCHI JUNIOR, W. O financiamento dos programas federais de esporte e lazer no Brasil (2004 a 2008). Revista Movimento, v. 16, n. 04, p. 73-92, out/dez. 2010.

ATHAYDE, P. F. A. Programa Segundo Tempo: conceitos, gestão e efeitos. 177

f. Dissertação (Mestrado em Educação Física) - Faculdade de Educação Física, Universidade de Brasília, Brasília, 2009. ATHAYDE, P.; MASCARENHAS, F.; SALVADOR, E. Primeiras aproximações de uma análise do financiamento da política nacional de esporte e lazer no Governo Lula. Revista Brasileira de Ciências do Esporte, v. 37, n. 1, p. 2-10, jan. 2015.

BRASIL. Constituição Federal. Disponível em http://www.planalto.gov.br/ccivil_03/ constituicao/ConstituicaoCompilado. htm. Acesso em: 08 abr. 2013.

BRASIL. Lei n. ${ }^{\circ}$ 9.615, de 24 de março de 1998 (Lei Pelé). Institui normas gerais sobre o desporto e dá outras providências. Disponível em http://www.planalto. gov.br/ccivil_03/leis/L9615consol.htm. Acesso em: 03 abr. 2016.

CASTRO, S. B. E. de. Políticas públicas para o esporte e lazer e o ciclo orçamentário brasileiro (2004-2011): prioridades e distribuição de recursos durante os processos de elaboração e execução orçamentária. 378 f. Tese (Doutorado em Educação Física) - Universidade Federal do Paraná, Curitiba, 2016.

CASTRO, S. B. E. de; SOUZA, D. L. de; STAREPRAVO, F. A.; COAKLEY, J. Mega sporting events and public funding of sport in Brazil (2004-2011). Leisure Studies, 2015.

FLOSS, A. M. Análise da Destinação de Recursos do Fundo Estadual de Incentivo ao Esporte de Santa Catarina (FUNDESPORTE) e a Correlação com Indicadores Socioeconômicos no período de 2005 a 2011. Trabalho de Conclusão de Curso. Universidade do Estado de Santa Catarina. Florianópolis, 2012

MATIAS, W.; ATHAYDE, P. A LEI DE INCENTIVO FISCAL EO (NÃO) DIREITO AO ESPORTE NO BRASIL. Movimento, v. 21, p. 95-109, 2015.

MENDES, A. D.; AZEVEDO, P. H. Políticas públicas de esporte e lazer \& políticas públicas educacionais: promoção da educação física dentro e fora da escola ou dois pesos e duas medidas? Rev. Bras. Ciênc. Esporte, Porto Alegre, v. 32, n. 1, Set. 2010

MINISTÉRIO DO ESPORTE. III Conferência Nacional do Esporte: por um time chamado Brasil. Disponível em: http://www.esporte.gov.br/ conferencianacional/conferencia2/ documentoFinal.jsp. Acesso em 12 de set. de 2013

SANTA CATARINA, Sistema Estadual de Incentivo à Cultura, ao Turismo e ao Esporte. Disponível em: http://www.sef. sc.gov.br/sistemas/sigef. Acesso em 25 de ago. de 2013

SANTA CATARINA. Decreto 1291-08, de 18 de abril de 2008. Regulamenta a Lei $\mathrm{n}^{\circ} 13.336$, de 8 de março de 2005, alterada pela Lei $n^{\circ} 14.366$, de 
25 de janeiro de 2008, e disciplina a celebração de instrumento legal pelo Governo do Estado que tenha como objeto o financiamento de projeto, por meio do Fundo Estadual de Incentivo à Cultura - FUNCULTURAL, o Fundo Estadual de Incentivo ao Turismo FUNTURISMO e Fundo Estadual de Incentivo ao Esporte - FUNDESPORTE, no âmbito do Sistema Estadual de Incentivo à Cultura, ao Turismo e ao Esporte - SEITEC, e adota outras providências. Disponível em www.sol. sc.gov.br. Acesso em 15 set. de 2013.

SANTA CATARINA, Sistema Integrado De Planejamento e Gestão Fiscal- SIGEF. Disponível em: http://www.sef.sc.gov. br/sistemas/sigef. Acesso em 04 de set. de 2013.

SANTA CATARINA. FESPORTE. Nossa História. Disponível em http:// www.fesporte.sc.gov.br/index. php?option $=$ com_content $\&$ view $=$ arti cle\&id $=1 \&$ Itemid $=97$. Acesso em 14 abr. de 2013.

SANTA CATARINA. Lei 13.336, de 08 de março de 2005. Institui o Fundo Estadual de Incentivo a Cultura, Fundo Estadual de Incentivo ao Turismo e o Fundo Estadual de Incentivo ao Esporte, no âmbito do Sistema Estadual de Incentivo à Cultura, ao Turismo e ao Esporte e estabelece outras providências. Disponível em www.sol.sc.gov.br. Acesso em 10 abr. de 2013.

SANTA CATARINA. Lei 13.792, de 18 de julho de 2006. Estabelece políticas, diretrizes e programas para a cultura, o turismo e o desporto no Estado de Santa Catarina e estabelece outras providências. Disponível em www.sol. sc.gov.br. Acesso em 12 set. de 2013.
SANTA CATARINA. Lei 14.600, de 29 de dezembro de 2008. Modifica a estrutura do Sistema Estadual de Incentivo à Cultura, ao Turismo e ao Esporte - SEITEC, altera dispositivos da Lei $\mathrm{n}^{\circ}$ 13.336, de 2005, que institui o FUNCULTURAL, O FUNTURISMO e o FUNDESPORTE e adota outras providências. Disponível em www.sol. sc.gov.br. Acesso em 12 set. de 2013.

SANTA CATARINA. Caderno de Indicadores 2013. Secretaria de Estado da Fazenda. Diretoria de Planejamento Orçamentário. Florianópolis, 2013. Disponível em: http://www.sef. sc.gov.br/relatorios/dior/caderno-deindicadores-2013. Acesso em 10 set. 2013.

SANTOS, A. M. M. M. et al. Esportes no Brasil: situação atual e propostas para desenvolvimento, 1997. Disponível em: http://www.bndes.gov.br/SiteBNDES/ export/sites/default/bndes_pt/Galerias/ Arquivos/conhecimento/bnset/esporte. pdf. Acesso em 28 de out. de 2013.

SANTOS, E.S. dos.; STAREPRAVO, F. A.; SOUZA NETO, M. S. Programa "Segundo Tempo" e o vazio assistencial na região nordeste. Movimento, Porto Alegre, v. 21, n. 3, p. 759-771, jul./set. de 2015.

STAREPRAVO, F. A.; MEZZADRI, F. M.; MARCHI JÚNIOR, W. Criação e mudanças na estrutura do Ministério do Esporte do Brasil: tensões nas definições de espaços. Revista Brasileira de Educação Física e Esporte, São Paulo, v. 29, n. 2, p. 217-228, abr./jun. 2015. VERONEZ, L. F. C. Quando o Estado joga a favor do privado: as políticas de esporte após a Constituição de 1988. 2005. 376f. Tese (Doutorado em Educação 
Física)- Faculdade de Educação Física, Universidade Estadual de Campinas, Campinas, 2005.

WAGNeR, L. O Impacto do Programa

Estadual Esporte Escolar no Contexto da Rede Pública Estadual de Ensino

de Santa. Dissertação de Mestrado. Universidade do Estado de Santa Catarina. Florianópolis, 2006.

FUNDING OF SPORT IN SANTA CATARINA: the case of FUNDESPORTE in the years 2011 and 2012

\begin{abstract}
In Santa Catarina, the development of sport is linked to the State Department of Sport, Culture and Leisure, which through FUNDESPORTE, funds sports projects in the state. The goal of this research, which has a quantitative, descriptive and exploratory nature, was to investigate the distribution of resources by FUNDESPORTE in 2011 and 2012. During these years, it registered a total of 1,233 projects. From these, only 317 actually received public transfer. From the total sum of that period, $\mathrm{R} \$ 32.294 .026,97,94.4 \%$ were allocated to legal entities, and $5.6 \%$ were allocated to individuals. Both team sports and individual sports were covered by the fund, but some sports received significantly more resources than others. Most of the resources were allocated to projects that aimed at high performance sport and the hosting of major sporting events. This work points out issues that can serve as source for further research and analysis of similar cases.
\end{abstract}

Keywords: Public Policies; Funding; Sport

FINANCIAMIENTO DEL DEPORTE EN SANTA CATARINA: EI caso de FUNDESPORT en los anos 2011 y 2012.

\title{
RESUMEN
}

El Estado de Santa Catarina la politica deportiva esta vinculada al Departamento de Deportes,Cultura y Entretenimiento del Estado, que a travez del FUNDESPORTE promueve el desarrollo del deporte en Santa Catarina. Esta investigacion cuantitativa,descriptiva y exploratoria, tuvo como objetivo investigar la distribucion de los recursos de FUNDESPORTE en el 2011 y 2012. En los anos analizados FUNDESPORTE registro un total de 1233 proyectos, del total de estos solo 317 recibieron efectivamente la transferencia de fondos publicos. Del monto total, $\mathrm{R} \$ 32.294 .026,97$, el $94.4 \%$ fue transmitida a las personas juridicas y el $5.6 \%$ se asignaron a individuos. Ambos deportes colectivos e individuales fueron cubiertos por el fondo, y alguns deportes recibieron muchos más recursos que otros. El fondo en cuestion pasa una gran parte de su presupuesto a proyectos destinados al deporte de alto rendimiento y tambien para grandes eventos deportivos organizados en el Estado. Este trabajo señala los problemas que pueden servir como subsidios para futuros estudios y analises de casos similares.

Palabras clave: Políticas Públicas; Fondos; Deporte 